\title{
Plasmodium species mixed infections in two areas of Manhiça District, Mozambique
}

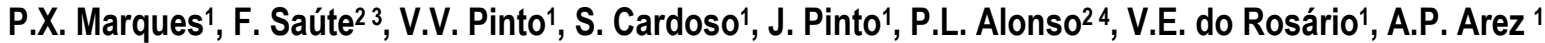 \\ ${ }_{1}^{1}$ Centro de Malária e outras Doenças Tropicais (CMDT), IHMT/UNL, Rua da Junqueira 96, 1349-008 Lisbon, Portugal. \\ ${ }_{3}^{2}$ Centro de Investigação em Saúde da Manhiça (CISM)/Ministério de Saúde, Maputo, Mozambique. \\ ${ }^{3}$ Instituto Nacional de Saúde, Ministério de Saúde, Maputo, Mozambique. \\ ${ }^{4}$ Unidad de Epidemiología y Bioestadística, Hospital Clínic, Barcelona, Spain.
}

Corresponding address: Dr. A.P. Arez. E-mail: aparez@ihmt.unl.pt; Tel.: +351 213652657; Fax: +351 213622458

Received: 2005.03.12; Accepted: 2005.04.25; Published: 2005.05.01

We compared the distribution patterns of individual Plasmodium species and mixed-species infections in two geographically close endemic areas, but showing environmental differences. Comparisons concerned circulating Plasmodium infections in both human and mosquito vector populations in the dry and wet seasons, at a microepidemiological level (households). Both areas revealed a very high overall prevalence of infection, all year-round and in all age groups. Plasmodium falciparum was the predominant species, being found in the vast majority of infected individuals regardless of the presence of other species. Plasmodium malariae and Plasmodium ovale occurred almost exclusively in mixed infections. Seasonal variation in P. malariae prevalence was observed in one area but not in the other. A decrease in P. malariae prevalence concurred with a marked increase of $P$. falciparum prevalence. However this was strongly dependent on age and when analysing infections at the individual level, a different pattern between coinfecting species was unveiled. Regarding transmission patterns, in both areas, $P$. falciparum gametocytes predominated in single infections regardless of age and P. malariae gametocyte carriage increased when its overall prevalence decreased.

K ey words: Plasmodium, mixed infections, transmission, M ozambique

\section{Introduction}

In natural parasite populations of Plasmodium interspecific (mixed) infections commonly occur. However as pointed out very recently by several authors $[1,2,3]$ there has been only sporadic interest in this subject.

In clinical, microscopically-based diagnostics, mixed malaria infections are often missed but sensitive PCRbased techniques $[4,5]$ and/or longitudinal studies have demonstrated that mixed infections are remarkably common [6, 7]. Experimental studies with humans [reviewed in 8 and 9] and rodents [10,11] indicated that different parasite species seem to interact, affecting mortality, pathology and infection dynamics. Effects of mixed infections on pathology were also recorded in field studies, namely attenuation of falciparum disease severity $[12,13,14,15]$.

When prevalence of mixed Plasmodium infections in humans is analysed in endemic areas, the pair falciparumvivax seems to be under-represented [13, 16, 17]. In contrast, an excess of mixed infections is often correlated with the pair falciparum-malariae [6, 18, 19, 20]. Also, seasonal variation between individual species prevalence was observed between $P$. falciparum and $P$. vivax in Vanuatu $[13,21]$ and between $P$. falciparum and $P$. malariae in Nigeria [6] and Burkina Faso [22]. However, geographical differences in these distribution patterns have also been reported [8]. Whether this alternation really occurs and has a biological meaning or if it is due to a sampling artefact remains controversial.

In previous studies carried out in Guinea-Bissau [4, 20], we observed that households were likely to work as individual units of transmission. In addition, different associations of Plasmodium species seemed to occur in infections detected in the human host or in the mosquito vector [20].
In this context, the main aim of this study was to determine whether different patterns of mixed infections might be affected by even minor differences in environmental conditions. For the purpose, we compared prevalence of different Plasmodium species and mixedinfections in two very close areas, but with slightly distinct environmental characteristics. We also analysed infections in both human and mosquito vector populations at the household level in order to determine which parasite populations were actually being transmitted between the two hosts and to better assess possible differences in the transmission of the several Plasmodium species. Further, the same households were sampled in the dry and wet seasons to assess possible effects of different transmission levels on parasite transmission among vertebrate hosts and mosquito vectors.

\section{Materials and Methods}

\section{Study area}

The study took place in two areas of the Manhiça district, in southern Mozambique, east Africa Manchiana and Ilha Josina. Both areas were subsequently included in an efficacy trial of a malaria vaccine candidate [23]. In both, climate is characterised by a hot and wet season (from October to May) and a dry and cold season (from June to September). Malaria is endemic with perennial transmission and marked seasonality. The average entomological inoculation rate in the district was estimated to be 15 infectious bites per person per year in 1998 [Aranda in 24]. Anopheles funestus sensu lato and Anopheles gambiae sensu lato are the main malaria vectors of the region [25].

Manchiana is a flat savannah area with moderate vegetation located approximately $10 \mathrm{~km}$ north of the 
village of Manhiça. This sandy area has two main permanent mosquito-breeding sites located on the east and west borders and most of the population lives about $1 \mathrm{Km}$ away from them.

Ilha Josina is an island in the Incomati River, which crosses the district from north to south. It is a marshy area located about $40 \mathrm{~km}$ northeast from Manchiana. The access is made through a small bridge or boats. There are local abundant mosquito breeding sites in addition to the surrounding river and abundant vegetation.

In both areas, there are two health facilities offering basic services and an elementary mother and child health care unit. Population is mainly made up of farmers growing maize and beans and also selling reeds in Ilha Josina. Housing conditions are generally poor and typically made of reed with thatched or corrugated roofs.

\section{Sampling}

The investigation was approved by the Ethical Committee of the Faculty of Medicine, Eduardo Mondlane University, Maputo. The local village chief and each person (or parent) was informed of the nature and aims of the study and told that participation was voluntary. An informed consent was obtained from each household chief.

In both areas, sampling took place in the dry (August 2001) and wet (February 2002) seasons. In each season, collections were made in a total of 12 households in Manchiana (10 households surveyed in both seasons) and in a total of 13 households in Ilha Josina (11 households surveyed in both seasons). All houses were mapped and their inhabitants fully identified (including the room in which they slept). In each household, blood fed resting Anopheles females were collected in the morning (6.00-7.00 am), followed by blood samples collection (fingerprick) from all inhabitants, for microscopic detection of gametocytes and for PCR analysis.

Assuming that the extrinsic incubation period at an average temperature of $28^{\circ} \mathrm{C}$ is of $9-10$ days for $P$. falciparum, 14-16 days for $P$. malariae and 12-14 days for $P$. ovale [26], mosquitoes were kept in paper-cups corresponding to each house/room during 8 days with glucose ad libitum. This should allow the development of oocysts from all species, resulting from infections acquired the night prior to collection. After this period dissections were performed to obtain midguts and salivary glands for PCR analysis. We assumed that parasites found in salivary glands were the result of previously acquired infections.

\section{Identification of Plasmodium species}

Detection of malaria infection and identification of Plasmodium species, both in blood samples and in mosquitoes, was carried out by nested-PCR amplification of the small subunit ribosomal RNA genes [5].

Parasite densities were determined in blood smears and asexual and sexual forms were recorded separately. Smears were Giemsa-stained and parasite densities were recorded as the number of parasites/ $\mu$ l of blood, assuming an average leukocyte count of $8000 / \mu$ l (all smears were examined against 500 leucocytes prior to be declared negative). Plasmodium falciparum (F) and $P$. malariae $(\mathrm{M})$ asexual parasitaemias were divided into groups according to densities: Low ( $F$ and $M<80$ parasites $/ \mu \mathrm{l})$; Moderate (F 80-3500 parasites / $\mu \mathrm{l}$ and M 80650 parasites/ $\mu \mathrm{l})$; High ( $\mathrm{F}>3500$ parasites $/ \mu \mathrm{l}$ and $\mathrm{M}>650$ parasites $/ \mu \mathrm{l})$. Infections detected only by PCR were grouped as Sub-Patent (SP).

\section{Identification of mosquito species}

Species identification of the members of the $A n$. gambiae and An. funestus complexes was performed by PCR according to previously described protocols $[27,28]$. One microlitre of dilutions of 1:25 in ddH2O of each DNA sample extracted from individual mosquitoes was used as DNA template in separate PCR reactions.

\section{Statistical analysis}

Since collections were carried out in households (clusters) which involves a higher variability than random sampling [29], overall prevalence in each area and season and their confidence intervals were determined considering global and cluster variance. Design effects were also determined. Since these had values around 1.0, meaning that sampling was approximate to simple random sampling, other proportions were determined considering that data arose from random sampling. Comparison of prevalences was made using the Pearson $\chi^{2}$ test. A significance level of 5\% was considered. Calculations were made using Epi Info Version 6.04d and Statistica 5.0 for Windows.

\section{Results}

A total of 308 blood samples were collected from 213 asymptomatic people in both areas and seasons (70 people from Manchiana in each season; 81 and 87 people from Ilha Josina in the dry and wet season, respectively). Age of the population sampled varied between 1 and 82 years-old with nearly $55 \%$ being less than 14 years-old.

A total of 1342 mosquitoes were collected and kept for sporogonic development: 423 and 112 mosquitoes in Manchiana (dry and wet season, respectively), and 269 and 538 mosquitoes in Ilha Josina (dry and wet season, respectively).

Table 1 - Prevalence of infection in Manchiana and Ilha Josina in the dry and wet seasons.

\begin{tabular}{|c|c|c|c|c|}
\hline & \multicolumn{4}{|c|}{ Prevalence (\%) } \\
\hline \multirow{2}{*}{$\begin{array}{l}\text { Area } \\
\text { Season }\end{array}$} & \multicolumn{2}{|c|}{ Manchiana } & \multicolumn{2}{|c|}{ Ilha Josina } \\
\hline & Dry & Wet & Dry & Wet \\
\hline & $\mathrm{n}=70$ & $\mathrm{n}=70$ & $\mathrm{n}=81$ & $\mathrm{n}=87$ \\
\hline Overall & $\begin{array}{c}71 \\
\{52-91\}\end{array}$ & $\begin{array}{c}80 \\
\{67-93\}\end{array}$ & $\begin{array}{c}91 \\
\{83-100\}\end{array}$ & $\begin{array}{c}91 \\
\{85-96\}\end{array}$ \\
\hline \multicolumn{5}{|l|}{ Single infections } \\
\hline $\mathbf{F}$ & 60 & 63 & 51 & 69 \\
\hline M & 0 & 1 & 1 & 0 \\
\hline \multicolumn{5}{|l|}{ Mixed infections } \\
\hline $\mathbf{F}+\mathbf{M}$ & 9 & 14 & 26 & 21 \\
\hline $\mathbf{F}+\mathbf{O}$ & 0 & 1 & 9 & 0 \\
\hline $\mathbf{F}+\mathbf{M}+\mathbf{O}$ & 3 & 0 & 5 & 1 \\
\hline $\begin{array}{l}\text { Overall infection } \\
\text { F }\end{array}$ & 71 & 79 & 90 & 91 \\
\hline $\begin{array}{c}\text { Overall infection } \\
\text { M }\end{array}$ & 11 & 16 & 32 & 22 \\
\hline $\begin{array}{c}\text { Overall infection } \\
\text { O }\end{array}$ & 3 & 1 & 14 & 1 \\
\hline
\end{tabular}

n: sample size; F: P. falciparum; M: P. malariae; O: P. ovale; $\mathrm{F}+\mathrm{M}$ : mixed infection by $P$. falciparum and $P$. malariae; $\mathrm{F}+\mathrm{O}$ : mixed infection by $P$. falciparum and $P$. ovale; $\mathrm{F}+\mathrm{M}+\mathrm{O}$ : mixed infection by $P$. falciparum, $P$. malariae and $P$. ovale. Ninety-five per cent Confidence Intervals of overall prevalence in square brackets (see Materials and Methods). 


\section{Infection in the human population}

As expected, PCR analysis consistently revealed higher infection rates than optical microscopy $(\mathrm{OM})$. This was especially evident for mixed infections (PCR versus OM - Manchiana: dry season $11 \%$ vs $4 \%$; wet season $16 \%$ vs $10 \%$; Ilha Josina: dry season $40 \%$ vs $7 \%$; wet season $22 \%$ vs $14 \%$ ) and overall prevalence of species other than $P$. falciparum (e.g. P. ovale was almost only detected by PCR).

In Manchiana the overall prevalence (determined by PCR) increased from $71 \%$ in the dry season to $80 \%$ in the wet season (Table 1). Plasmodium falciparum was the predominant species occurring in $100 \%$ and $98 \%$ of the infected population, either in single or mixed infections.
Prevalence of species other than $P$. falciparum and, consequently, of mixed infections also increased from $16 \%$ to $20 \%$ in the dry and wet seasons, respectively (Figure 1).

In Ilha Josina, an overall prevalence of $91 \%$ was maintained from one season to another (Table 1), but prevalence of mixed infections significantly decreased $\left(\chi^{2}=6.334, \mathrm{p}=0.012\right)$ in the wet season $(43 \%$ in the dry and $24 \%$ in the wet season) (Figure 1). This was concomitant with lower $P$. malariae and $P$. ovale prevalences in the wet season (P. malariae: $32 \%$ and $22 \%$, P. ovale: $14 \%$ and $1 \%$, in the dry and wet seasons, respectively) (Table 1).

Figure 1 - Prevalence of single and mixed infections among the overall infected population in Manchiana ( $\mathrm{n}=50$ in dry season and $n=56$ in wet season) and Ilha Josina ( $n=74$ in dry season and $n=79$ in wet season) and by age group (less or more than 14 years-old).

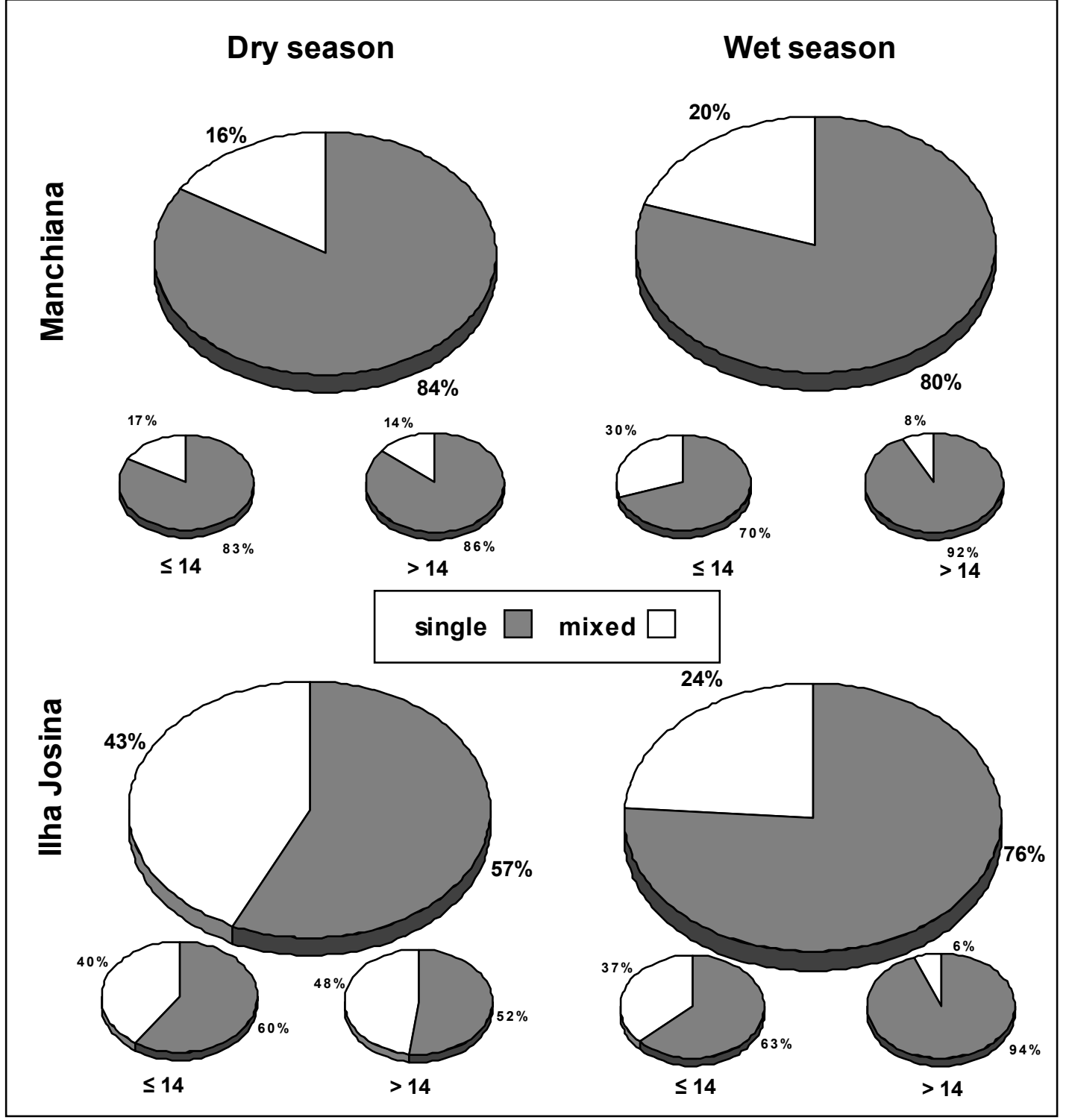

Overall prevalence of infection was high in all age groups. Among infected people in both areas and seasons, mixed infections were more prevalent in children less than 14 years old. From the dry to the wet season, a considerable decrease in prevalence of mixed infections occurred among adults ( $>14$ years-old), being significantly different from the one observed in children ( $\leq 14$ years-old) in Ilha Josina $(\chi 2=8.421, p=0.004)$. In
Manchiana, although not statistical significant, differences between age groups were still evident $(\chi 2=3.09, \mathrm{p}=0.079)$ (Figure 1).

Densities of $P$. falciparum asexual forms were higher in Ilha Josina than in Manchiana and decreased in the wet season in both areas (geometric mean and median Manchiana: dry season 858.37 and 619.97 parasites/ $\mu 1$ blood; wet season 256.06 and 136.68 parasites/ $\mu$ l blood; 
Ilha Josina: dry season 1040.80 and 694.65 parasites/ $\mu$ l blood; wet season 467.92 and 426.04 parasites/ $\mu 1$ blood). In Manchiana this decrease was coincident with a lower prevalence of Moderate and High parasite densities and a higher prevalence of Low (and Sub-Patent) densities (Figure 2). However, in Ilha Josina, the prevalence of Low-density infections also increased but prevalence of
Moderate and High densities remained unaltered. In both areas and both seasons, P. falciparum Moderate and High parasite densities predominated in children while SubPatent and Low densities predominated in adults (Figure 2).

Figure 2 - Distribution of $P$. falciparum density groups (Neg: non-infected, SP: sub-patent, L: low, M: moderate, H: high) by age groups (1-5 years old: black bars; 6-14 years old: grey bars; > 14 years old: white bars) in both areas and both seasons. Prevalence of each density group in the total population is shown below.

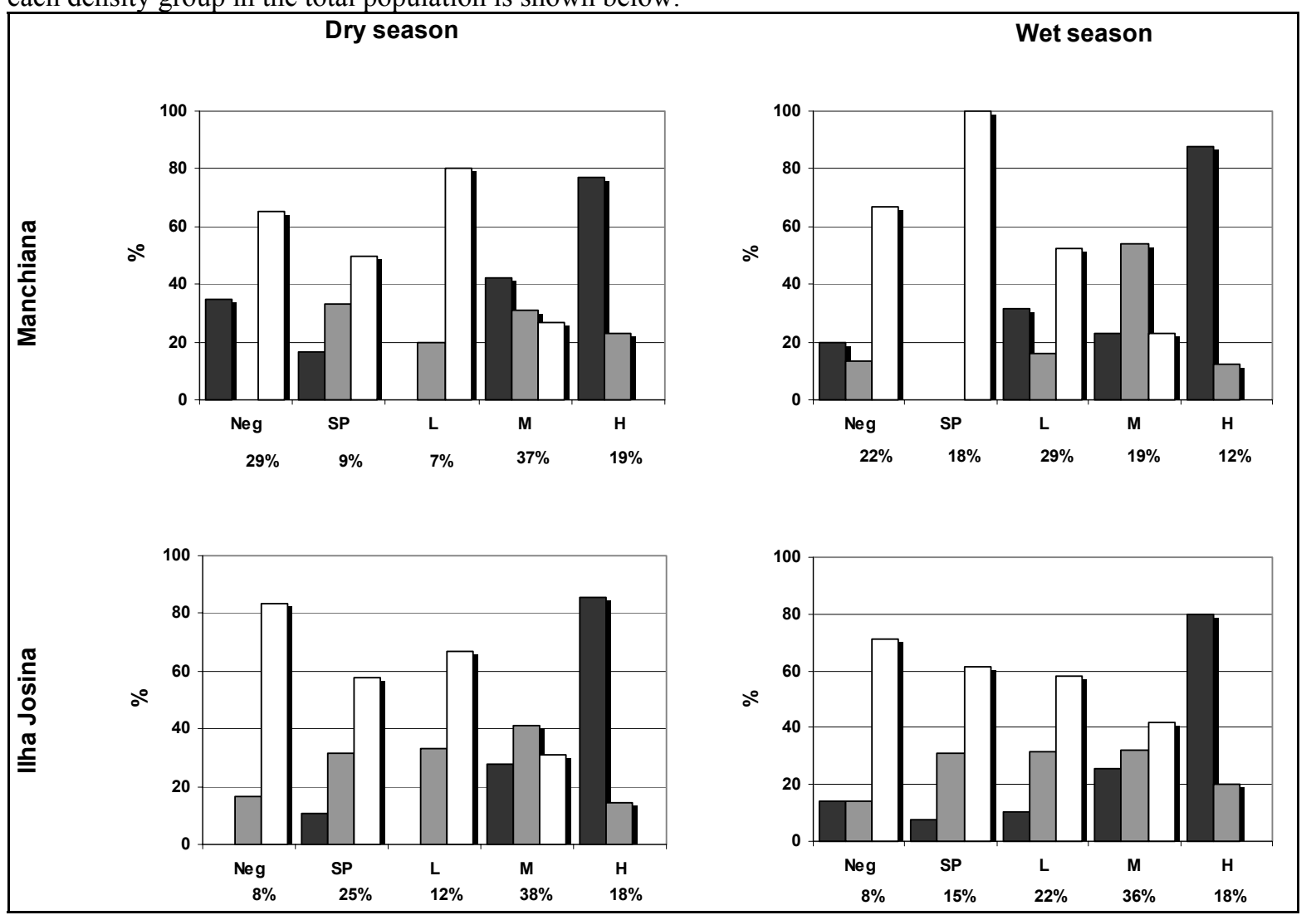

Densities of asexual P. malariae were recorded in a very small number of samples but also seemed to decrease in the wet season (Table 2). However, patency increased in both areas (patent infections, considering the total number of P. malariae infections: Manchiana - 38\% in the dry and $73 \%$ in the wet season; Ilha Josina - $23 \%$ in the dry and $68 \%$ in the wet season). Only one patent $P$. ovale infection was recorded (63 parasites/ $\mu 1$ blood), in Ilha Josina, in the dry season.

Table 2 Asexual forms densities (parasites/ $\mu$ l blood) and distribution of $P$. malariae density groups in both areas and both seasons.

\begin{tabular}{|c|c|c|c|c|}
\hline & & & Dry season & Wet season \\
\hline \multirow[t]{5}{*}{ Manchiana } & \multirow{3}{*}{$\begin{array}{l}\text { Density groups by age } \\
\text { group }\end{array}$} & $1-5$ years old & 7Neg, 2SP & $2 \mathrm{Neg}, 1 \mathrm{~L}, 4 \mathrm{M}, 1 \mathrm{H}$ \\
\hline & & 6-14 years old & $1 \mathrm{SP}, 2 \mathrm{M}, 1 \mathrm{H}$ & $2 \mathrm{Neg}, 1 \mathrm{SP}, 1 \mathrm{~L}, 1 \mathrm{M}$ \\
\hline & & $>14$ years old & $13 \mathrm{Neg}, 2 \mathrm{SP}$ & $10 \mathrm{Neg}, 2 \mathrm{SP}$ \\
\hline & \multicolumn{2}{|c|}{ Geometric mean } & $448.37(n=3)$ & $225.44(n=8)$ \\
\hline & \multicolumn{2}{|c|}{ Median } & $285.71(\mathrm{n}=3)$ & $339.58(n=8)$ \\
\hline \multirow{5}{*}{ Ilha Josina } & \multirow{3}{*}{$\begin{array}{l}\text { Density groups by age } \\
\text { group }\end{array}$} & $1-5$ vears old & $2 \mathrm{M}, 1 \mathrm{H}$ & $1 \mathrm{Neg}, 2 \mathrm{~L}, 3 \mathrm{M}, 4 \mathrm{H}$ \\
\hline & & 6-14 years old & 2Neg, 9SP, 1L & 2Neg, 4SP, $1 \mathrm{~L}, 3 \mathrm{M}$ \\
\hline & & $>14$ years old & $5 \mathrm{Neg}, 11 \mathrm{SP}, 1 \mathrm{~L}, 1 \mathrm{M}$ & $5 \mathrm{Neg}, 2 \mathrm{SP}$ \\
\hline & \multicolumn{2}{|c|}{ Geometric mean } & $391.25(\mathrm{n}=6)$ & $270.55(\mathrm{n}=13)$ \\
\hline & \multicolumn{2}{|c|}{ Median } & $238.50(n=6)$ & $334.00(n=13)$ \\
\hline
\end{tabular}

n: sample size; Neg: non-infected, SP: sub-patent, L: low, M: moderate, H: high 
In mixed infections, for both areas and seasons, Moderate and High P. malariae densities occurred in individuals with Moderate and High $P$. falciparum densities (only two cases with Low and one case with Sub-Patent $P$. falciparum densities). All but one of these individuals were aged between 1 and 14 years-old. Similarly, P. ovale infections occurred mostly in children with Moderate and High P. falciparum parasitaemias.

Overall prevalence of gametocyte-carriers increased in the wet season in both areas (Figure 3). In Manchiana this increase reflects the increase of $P$. falciparum gametocyte prevalence while in Ilha Josina it reflects the increase of $P$. malariae gametocyte prevalence. No $P$. ovale gametocytes were detected. Gametocyte prevalence predominated in children, except in Ilha Josina, in the dry season ( $\leq 14$ versus $>14$ - Manchiana: dry season $36 \%$ vs $0 \%$; wet season $53 \%$ vs $21 \%$; Ilha Josina: dry season $18 \%$ vs $31 \%$; wet season $48 \%$ vs $8 \%$ ). Plasmodium falciparum gametocytes seemed to predominate in single infections, even after adjusting for age (gametocyte prevalence in single versus mixed infections - Manchiana: dry season $75 \%$ vs $25 \%$; wet season $71 \%$ vs $29 \%$; Ilha Josina: wet season $69 \%$ vs 31\%), except in Ilha Josina, in the dry season $(33 \%$ vs $67 \%)$.

Figure 3 - Prevalence of gametocyte-carriers of each Plasmodium species (F - P. falciparum; $\mathrm{M}-P$. malariae; without prevalence of non-gametocyte carriers). Only population with patent parasitaemia was considered (Manchiana-dry season: $P$. falciparum $-\mathrm{n}=44 ;$. malariae $-\mathrm{n}=3$; Manchiana-wet season: $P$. falciparum $-\mathrm{n}=43 ; P$. malariae $-\mathrm{n}=8$; Ilha Josina-dry season: $P$. falciparum $-\mathrm{n}=54 ;$. malariae $-\mathrm{n}=6$; Ilha Josina-wet season: $P$. falciparum $-\mathrm{n}=66 ; P$. malariae $-\mathrm{n}=13$ ).

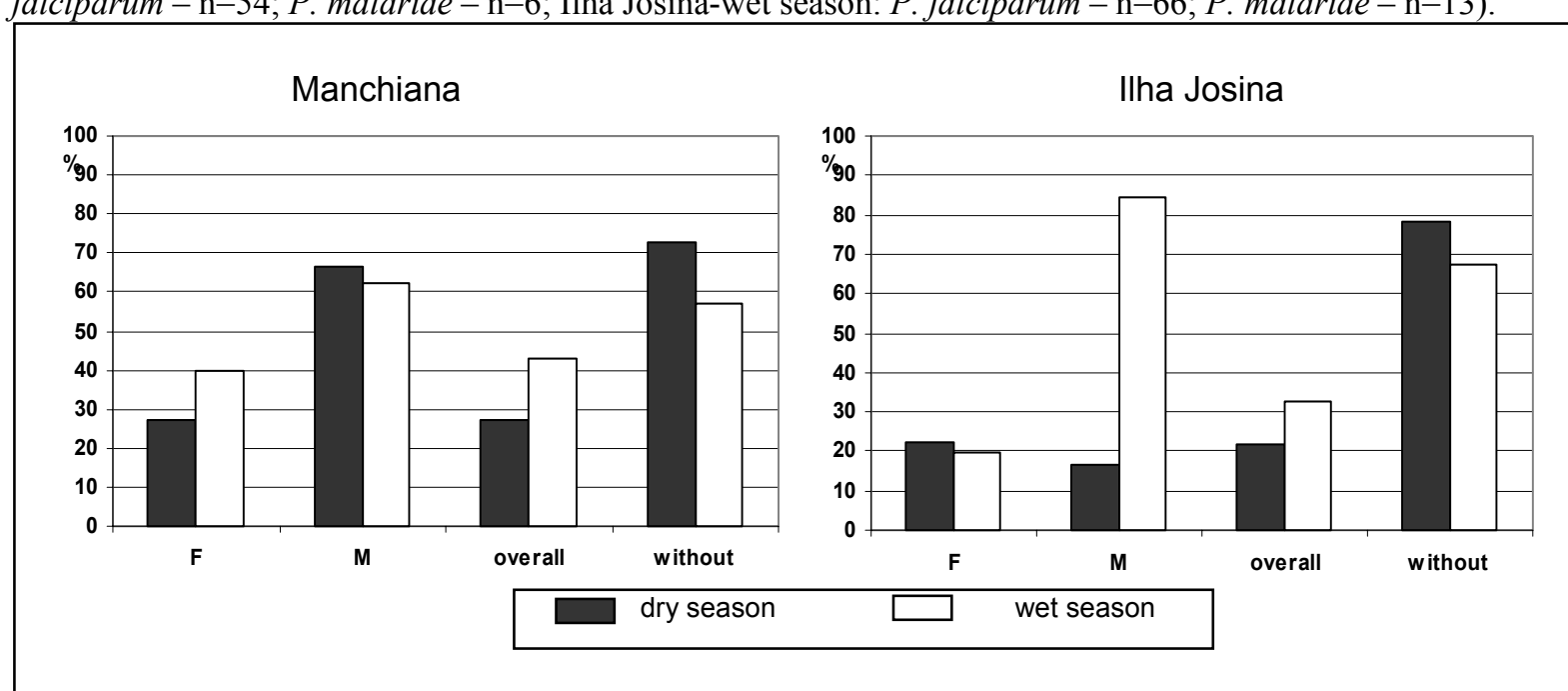

\section{Infection in the mosquito population}

A sub-sample of 122 mosquitoes was identified to species by PCR. Anopheles funestus sensu stricto was the predominant species, accounting for $116(95 \%)$ of the identifications. Anopheles arabiensis was the other species identified, but only in 6 specimens $(5 \%)$ collected from Manchiana in the wet season.

A total of 1337 midguts and 1341 salivary glands were analysed for the two seasons and study areas.

In Manchiana, for the dry season, midgut and salivary glands infection rates of $8 \%(33 / 423,95 \%$ CI $4-$ $12)$ and $10 \%(43 / 423,95 \%$ CI $4-18)$, respectively, were determined. In the wet season, midgut infection rates were $9 \%(10 / 110,95 \% \mathrm{CI}-7-26)$ and $7(70 \%)$ of the infected mosquitoes were collected from the same house. An infection rate of $1 \%(1 / 112,95 \%$ CI -2-4) was determined in salivary glands.

In Ilha Josina, in the dry season, a midgut and salivary glands infection rate of $12 \%(33 / 266,95 \%$ CI -934 ; with 23 of the infected mosquitoes were collected in only two houses) and 6\% (16/269, 95\% CI -7-19; with 15 of the infected mosquitoes were collected in a single house), respectively, were determined. In the wet season, midguts and salivary glands infection rates of $5 \%$ (26/538, 95\% CI 2-7) and $4 \%(23 / 537,95 \%$ CI -0.6-9; with 13 of the infected mosquitoes collected from the same house) respectively, were determined.

Regardless of site or season, Plasmodium falciparum single infections were highly predominant (94\%,
174/185). Other Plasmodium species single infections (4 $P$. malariae and $1 P$. ovale) were found in midguts only from Manchiana, in the dry season. Mixed infections between $P$. falciparum and $P$. malariae were also detected in just a few midguts: 2 in Manchiana in the dry season and 4 in the Ilha Josina in the wet season.

\section{Discussion}

In the great majority of occasions, malaria control relies mainly on general measures that often fail to consider micro-epidemiological features that may influence its outcome. In this context, it may be particularly important to assess the prevalence of certain genotypes or mixed-species infections before control measures are implemented.

In light of this, the present study aimed to assess whether minor micro-epidemiological differences could relate to differential distribution of malaria parasites and we saw that seasonal variation in $P$. malariae prevalence was observed in one area but not in the other. A decrease in $P$. malariae prevalence concurred with a marked increase of $P$. falciparum prevalence but this was strongly dependent on age. Further, an increase of $P$. malariae gametocyte carriage was observed when its overall prevalence decreased. In both areas $P$. falciparum gametocytes predominated in single infections regardless of age.

The overall prevalence of infection was verified to be very high in both studied areas and was detected all year-round. In Ilha Josina, a marshy area with abundant 
mosquito breeding sites, both higher infection prevalence and parasite densities occurred, which reflect conditions more prone to intense transmission. In this area, the prevalence of $P$. malariae and $P$. ovale (especially the latter) markedly decreased in the wet season while prevalence of single $P$. falciparum infections increased. This strongly suggests that an alternation in the relative contribution of each species to the total parasite indexes occurred in this area. This alternation is neither attributable to differences in vector behaviour since the same mosquito species were found in both areas, nor to drug use or access to health facilities since both areas have similar characteristics regarding these factors.

Previous studies $[8,30]$ have suggested that $P$. malariae, which is able to develop chronic infections, can be found at higher prevalences when transmission and overall infection rates are lower and it is alleviated from the suppressive effect of $P$. falciparum. A similar phenomenon may explain the increase in $P$. ovale from the wet to the dry season since this parasite is able to relapse after long periods of dormancy in the liver [31]. In Manchiana, a sandy area with fewer mosquito breeding sites, where transmission and prevalence of infection are lower, the establishment of $P$. malariae infections may be facilitated, while in Ilha Josina, the high transmission during the wet season favours $P$. falciparum, which transmits more rapidly and suppresses $P$. malariae to undetectable levels. However, the decrease in the prevalence of mixed infections in Ilha Josina was observed mainly in adults, strongly supporting the notion that suppression of other Plasmodium species by $P$. falciparum only occurs when a certain level of immunity is reached and is able to control both species parasitaemia [6]. This is corroborated by the fact that, in mixed infections, high parasitaemias of one species occurred almost exclusively in individuals, mainly children, who also presented high parasitaemias of the other species.

A more comprehensive analysis of infections in mosquitoes collected in the same households could have helped to determine which parasite populations were actually being transmitted between the two host populations and to better assess possible differences in the transmission of the several Plasmodium species. Unfortunately, species other than P. falciparum were found at very low prevalence in mosquitoes thus precluding any comparisons. Moreover, most of the data derives from one or two houses only which could have biased the data on mosquito infection rates. Alternatively, transmission may be assessed through the analysis of gametocyte-carriage. This analysis limits the amount of conclusive information since gametocyte-patency may not correlate directly to mosquito infections [20] and the detection threshold of OM seriously reduces the sample size. Sensitive molecular tools are only available for the detection of $P$. falciparum gametocytes $[32,33]$ but not the other species. Nonetheless, some interesting observations were done.

In Ilha Josina in the wet season, both the P. malariae patent parasitaemia and the proportion of $P$. malariae gametocyte-carriers increased, despite the reduction in $P$. malariae prevalence, which may reflect an enhancement of transmissibility due to the increased pressure exerted by $P$. falciparum. Once more this is only evident in individuals under 14 years-old, the most susceptible portion of population.
McKenzie et al. [34], following analysis of records obtained from adults sequentially or simultaneously inoculated with both species, reported that prior or concurrent $P$. malariae infection enhanced production of $P$. falciparum gametocytes. In contrast, Price et al. [35] reported that mixed $P$. falciparum $+P$. vivax infections among Thai individuals are associated with a reduction in the prevalence of $P$. falciparum gametocytes. In agreement with the latter report, in the present study we observed that $P$. falciparum gametocytes seemed more likely to be present in single than in mixed infections and that this was independent of individuals age. Collectively, the implications of these observations may have a profound repercussion in the outcome of disease control. If the simultaneous infection by other species inhibits falciparum-gametocyte production and if control measures affect and reduce more effectively Plasmodium species other than $P$. falciparum, this inhibitory effect may disappear.

The results of the present work suggest that slightly distinct environmentally characteristics affect transmission patterns, and may have an effect in the way different human malaria species establish in the human population. The relevance of these data should be taken into account when general control strategies are planned. Control interventions may alter the proportions of parasite populations in a given region, which could have consequences on the acquisition of protective immunity or malaria pathology.

In spite of the microepidemiological approach, the complexity of the three biological malaria entities (parasite, human and mosquito) raises questions that are difficult to address in a field setting. The use of experimental models in which some of the variables can be controlled would benefit future studies in humans.

\section{Acknowledgements}

We are grateful to the population of Manchiana and Ilha Josina who accepted to participate in this study and the field-workers and technicians from CISM for their technical assistance. We thank Prof. António Grácio and Dra. Carla Sousa for the training in morphological identification of Anopheline mosquitoes (Unit of Medical Entomology, Instituto de Higiene e Medicina Tropical, Lisboa).

This study was supported by POCTI/1999/ESP/35789/99. A.P. Arez and J. Pinto were funded by FCT/MCIES, Portugal (SFRH/BPD/1624/2000 and SFRH/BPD/10086/2002).

\section{Conflict of interest}

The authors have declared that no conflict of interest exists.

\section{References}

1. Mayxay M, Pukrittayakamee S, Newton PN et al. Mixed-species malaria infections in humans. Trends Parasitol 2004; 20(5): 233240.

2. Snounou G, White NJ. The co-existence of Plasmodium: sidelights from falciparum and vivax malaria in Thailand. Trends Parasitol 2004; 20(7): 333-339.

3. Zimmerman PA, Mehlotra RK, Kasehagen LJ et al. Why do we need to know more about mixed Plasmodium species infections in humans? Trends Parasitol 2004; 20(9): 440-447.

4. Snounou G, Pinheiro L, Gonçalves A et al. The importance of sensitive detection of malaria parasites in the human and insect hosts in epidemiological studies, as shown by the analysis of field 
samples from Guinea Bissau. Trans R Soc Trop Med Hyg. 1993; 87(6): 649-653.

5. Snounou G, Viriyakosol S, Zhu XP et al. High sensitivity of detection of human malaria parasites by the use of nested polymerase chain reaction. Mol Biochem Parasitol 1993; 61(2): 315-320.

6. Molineaux L, Storey J, Cohen JE et al. A longitudinal study of human malaria in the west african savanna in the absence of control measures: relationships between different Plasmodium species, in particular P. falciparum and P. malariae. Am J Trop Med Hyg 1980; 29(5): 725-737.

7. Looareesuwan S, White NJ, Chittamas $S$ et al. High rate of Plasmodium vivax relapse following treatment of falciparum malaria in Thailand. Lancet 1987; 2: 1052-1055.

8. Richie TL. Interactions between malaria parasites infecting the same vertebrate host. Parasitology 1988; 96(Pt 3): 607-639.

9. Collins WE, Jeffery GM. A retrospective examination of sporozoite- and trophozoite-induced infections with Plasmodium falciparum in patients previously infected with heterologous species of Plasmodium: effect on development of parasitologic and clinical immunity. Am J Trop Med Hyg 1999; 61 (1 Suppl): 36-43.

10. Snounou G, Bourne T, Jarra $W$ et al. Identification and quantification of rodent malaria strains and species using gene probes. Parasitology 1992; 105(Pt3): 21-27.

11. Dennison JMTJ, Hommel M. Cerebral sequestration of murine malaria parasites after receptor amplification in mixed infections. Am J Trop Med Hyg 1993; 87: 665-666.

12. Black J, Hommel M, Snounou G et al. Mixed infections with Plasmodium falciparum and P. malariae and fever in malaria. Lancet 1994; 343(8905): 1095.

13. Maitland K, Williams TN, Bennett $\mathrm{S}$ et al. The interaction between Plasmodium falciparum and P. vivax in children on Espiritu Santo island, Vanuatu. Trans R Soc Trop Med Hyg 1996; 90(6): 614620.

14. Luxemburger C, Ricci F, Nosten F et al. The epidemiology of severe malaria in an area of low transmission in Thailand. Trans $\mathrm{R}$ Soc Trop Med Hyg 1997; 91(3): 256-262.

15. Price RN, Nosten F, Luxemburger $C$ et al. Artesunate/mefloquine treatment of multi-drug resistant falciparum malaria. Trans R Soc Trop Med Hyg 1997; 91(5): 574-577.

16. McKenzie FE, Bossert WH. Mixed-species Plasmodium infections of humans. J Parasitol 1997; 83(4): 593-600.

17. McKenzie FE, Bossert WH. Multispecies Plasmodium infections of humans. J Parasitol 1999; 85(1): 12-18.

18. Barnish G, Maude GH, Bockarie MJ et al. Malaria in a rural area of Sierra Leone. II. Parasitological and related results from preand post-rains clinical surveys. Ann Trop Med Parasitol 1993; 87(2): 137-148.

19. Pinto J, Sousa CA, Gonçalves L et al. Mixed-species malaria infections in the human population of São Tomé island, West Africa. Trans R Soc Trop Med Hyg 2000; 94(3): 256-257.

20. Arez AP, Pinto J, Pålsson K et al. Transmission of mixed Plasmodium species and Plasmodium falciparum genotypes. Am J Trop Med Hyg 2003; 68(2): 161-168.

21. Maitland K, Williams TN, Newbold CI. Plasmodium vivax and $P$. falciparum: biological interactions and the possibility of crossspecies immunity. Parasitol Today 1997; 13(6): 227-231.

22. Boudin C, Robert V, Verhave JP et al. Plasmodium falciparum and P. malariae epidemiology in a West African village. Bull World Health Organ 1991; 69(2): 199-205.

23. Alonso PL, Sacarlal J, Aponte JJ et al. Efficacy of the RTS,S/AS02A vaccine against Plasmodium falciparum infection and disease in young African children: randomised controlled trial. Lancet 2004; 364(9443): 1411-1420.

24. Mayor A, Saute F, Aponte JJ et al. Plasmodium falciparum multiple infections in Mozambique, its relation to other malariological indices and to prospective risk of malaria morbidity. Trop Med Int Health 2003; 8(1): 3-11.

25. Mendis C, Jacobsen JL, Gamage-Mendis A et al. Anopheles arabiensis and An. funestus are equally important vectors of malaria in Matola coastal suburb of Maputo, southern Mozambique. Med Vet Entomol 2000; 14(2): 171-180.
26. Gilles HM. The malaria parasites. In: Gilles HM, Warrell DA, eds. Bruce-Chwatt's Essential Malariology, 3rd ed. Kent: Edward Arnold, 1993: 12-34.

27. Scott JA, Brogdon WG, Collins FH. Identification of single specimens of the Anopheles gambiae complex by the polymerase chain reaction. Am J Trop Med Hyg. 1993; 49(4): 520-529.

28. Koekemoer LL, Kamau L, Hunt RH et al. A cocktail polymerase chain reaction assay to identify members of the Anopheles funestus (Diptera: Culicidae) group. Am J Trop Med Hyg. 2002; 66(6): 804-811.

29. Clark RG, Steel DG. The use of households as sampling units. Int Stat Rev 2002; 70(2): 289-314.

30. Mason DP, McKenzie FE, Bossert WH. The blood-stage dynamics of mixed Plasmodium malariae-Plasmodium falciparum infections. J Theor Biol 1999; 198(4): 549-566.

31. Collins WE, Jeffery GM. A Retrospective Examination of Sporozoite-Induced and Trophozoite-Induced Infections with Plasmodium ovale: Development of Parasitologic and Clinical Immunity during Primary Infection. Am J Trop Med Hyg 2002; 66(5): 492-502.

32. Babiker HA, Abdel-Wahab A, Ahmed S et al. Detection of low level Plasmodium falciparum gametocytes using reverse transcriptase polymerase chain reaction. Mol Biochem Parasitol 1999; 99(1): $143-148$.

33. Menegon M, Severini C, Sannella A et al. Genotyping of Plasmodium falciparum gametocytes by reverse transcriptase polymerase chain reaction. Mol Biochem Parasitol 2000; 111(1): 153-161.

34. McKenzie FE, Jeffery GM, Collins WE. Plasmodium malariae infection boosts Plasmodium falciparum gametocyte production. Am J Trop Med Hyg 2002; 67(4): 411-414.

35. Price R, Nosten F, Simpson JA et al. Risk factors for gametocyte carriage in uncomplicated falciparum malaria. Am J Trop Med Hyg 1999; 60(6): 1019-1023. 